\title{
Microbial diversity studies of the porcine gastrointestinal ecosystem during weaning transition
}

\author{
Sergey R. Konstantinov ${ }^{\mathrm{a} *}$, Christine F. FAVIER ${ }^{\mathrm{b}}$, Wei Yun ZHU ${ }^{\mathrm{c}}$, \\ Barbara A. WILLIAMS ${ }^{\mathrm{d}}$, Jeannette KLÜß ${ }^{\mathrm{e}}$, \\ Wolfgang-Bernhard SOUFFRANT ${ }^{\mathrm{e}}$, Willem M. DE VOS ${ }^{\mathrm{a}}$, \\ Antoon D.L. AKKERMANS ${ }^{\mathrm{a}}$, Hauke SMIDT ${ }^{\mathrm{a}}$ \\ a Laboratory of Microbiology, Wageningen University, Wageningen, The Netherlands \\ b INRA-UMRVP, Rennes, France \\ c College of Animal Science and Technology, Nanjing Agricultural University, Nanjing, China \\ dAnimal Nutrition Group, Wageningen University, Wageningen, The Netherlands \\ e Research Institute for the Biology of Farm Animals, Department of Nutritional Physiology \\ "Oskar Kellner", Dummerstorf, Germany
}

(Received 5 January 2004; accepted 27 May 2004)

\begin{abstract}
At the time of weaning, major quantitative and qualitative changes occur in the composition of the intestinal microbiota of piglets, influenced by diet, environmental factors, and the host. Within a short period of time, the intestinal microbiota must ultimately develop from a simple, unstable community into a complex and stable one. Here we present data on the development of the intestinal microbiota based on 16S rRNA gene sequence diversity. In addition to a PCR-based analysis of the 16S rRNA gene by cloning and denaturing gradient gel electrophoresis (DGGE), data on fluorescent in situ hybridisation (FISH) are presented to quantify the total bacterial communities, major Lactobacillus populations and specific Lactobacillus species. The results reported here indicate that the addition of non-digestible, fermentable carbohydrates (= prebiotics) leads to an enrichment of lactobacilli in the small intestine, and increased stability and diversity of the bacterial community in the colon. The data support the hypothesis that changes of the diet can modulate the composition of the microbiota in the intestine. These findings may have potentially major implications for the development of dietary strategies aiming to improve animal health during the weaning process.
\end{abstract}

\section{S rRNA gene / DGGE / prebiotics / pig GI tract microbiota / weaning}

Résumé - Études de la diversité microbienne de l'écosystème gastro-intestinal porcin au moment du sevrage. Au moment du sevrage, des changements majeurs, influencés par des facteurs alimentaires et environnementaux et par l'hôte, interviennent dans la composition de la flore intestinale des porcelets. A partir de la naissance, celle-ci doit se développer d'une communauté simple et instable à une autre, complexe et stable. Dans cette revue, nous présentons des résultats portant sur le développement de la flore intestinale et basés sur l'analyse de la diversité des séquences d'ADNr 16S. En plus des analyses d'ADNr 16S basées sur la PCR par clonage et électrophorèse en

\footnotetext{
* Corresponding author: sergey.konstantinov@wur.nl
} 
gel de gradient de dénaturation (DGGE), des résultats d'hybridation in situ (FISH) sont présentés pour quantifier les populations majeures de Lactobacillus. Les résultats indiquent que l'addition de glucides non digestibles mais fermentescibles (= prébiotiques) ont conduit à un développement de lactobacilli dans l'intestin grêle, et à une diversité et une stabilité accrues de la flore dans le colon. Ces résultats supportent l'hypothèse selon laquelle des changements alimentaires peuvent modifier la composition de la flore de l'intestin. Ces observations ont des implications majeures pour la santé pendant le processus de sevrage.

\section{S rDNA / microflore / prébiotiques / porc / sevrage}

\section{INTRODUCTION}

The porcine gastro-intestinal (GI) tract represents a dynamic ecosystem containing a complex community of micro-aerophilic and anaerobic microbes that are involved in the fermentation of ingested feed and the components secreted by the host into the GI tract. The insight into the structure and function of the GI tract microbial communities and into the activity of specific microbial species within this ecosystem is necessary for the development of rational alternatives to in-feed antibiotics, such as probiotics and prebiotics. In the past, the microbial community in the GI tract of pigs has been studied intensively using traditional culture techniques, and it has been shown that the majority of the faecal and colonic microbiota isolated from adult swine were Grampositive obligate anaerobes (reviewed by [20]). Most of the isolates were found to belong to the genera Streptococcus, Lactobacillus, Fusobacterium, Eubacterium, and Peptostreptococcus. The Gram-negative organisms, mainly belonging to the Bacteroides and Prevotella groups, comprise about $10 \%$ of the total culturable bacteria. However, many of the strictly anaerobic GI tract bacteria are still difficult to cultivate and therefore remain undetectable with conventional microbiological cultivation techniques $[16,22]$. This changed dramatically after the first introduction of $16 \mathrm{~S}$ ribosomal RNA (rRNA) as molecular markers in microbial taxonomy by Woese [25], and the first attempts to apply this sequence information in microbial ecology [15]. These new approaches have only recently been introduced in studies on the
GI tract and have led to new insights on the pig intestinal microbial ecology, the effect of different dietary strategies and host factors on the bacterial communities composition [4,7-11,18]. A summary of the uses and drawbacks of various techniques for the analysis of the pig intestinal ecosystem is given in Table I and an example of a denaturing gradient gel electrophoresis (DGGE) analysis of $16 \mathrm{~S}$ rRNA gene amplicons from ileal and colonic lumen samples of four weaning piglets is shown in Figure 1.

In commercial swine production, piglets are weaned early, usually by transport to a production farm, followed by an abrupt introduction of a solid diet. This combination of stress factors often leads to diarrhoea and growth reduction [19]. In order to enhance growth and suppress the activity of the gut microbiota, antimicrobial compounds have been fed to weaning pigs [1]. Nowadays, the emergence of antibiotic resistance in human commensal and pathogenic bacteria has raised public concern over the impact of antimicrobial use in agriculture, and intensified the search for alternative nutritional strategies such as the addition of probiotics and prebiotics [23, 24]. Insight into this issue needs both experience in animal nutrition, and knowledge of the factors affecting the composition and activity of the GI tract microbial community (also called microbiota). Which factors determine the composition of the microbiota and which factors play a role in the invasion of pathogens in the GI tract? Invasion by pathogens is very much dependent on the condition of the animal, including the composition and activity of the GI tract microbiota. Can we manipulate this community 
Table I. An overview of the uses and drawbacks of various techniques in the analysis of intestinal microbiota.

\begin{tabular}{lcc}
\hline Methods Uses & Drawbacks
\end{tabular}

Cultivation

Direct molecular approaches

- DGGE/ TGGE/TTGE

- T- RFLP

- FISH

- Dot-blot hybridisation

Detection; quantification of the relative abundance of rRNA

Detection; estimates the relative abundance

Phylogenetic identification

Rapid comparative analysis

- Non 16S rRNA gene based diversity analysis

- Diversity DNA arrays further analysis

Rapid assessment of the bacterial communities composition; uncultured bacteria can be detected; pre-treated samples can be stored for later analysis band extraction from the gel; Southern blot hybridisation with a potential for high throughput; standardised comparison between gels; size fragment analysis

Detection; enumeration; possibilities for an automated comparative analysis
"Gold standard"; recovery of isolates for

Rapid and reproducible diversity assessment; easy comparative analysis; allows

Fast and sensitive fingerprinting method

Laborious without automation; requires sequence information; probe design and validation

Probe design and validation; relative abundance difficult to relate to cell numbers; laborious at species level

Laborious, PCR biases

Large scale monitoring is laborious; PCR-biases

Requires the use of additional 16S rRNA- based analysis

High throughput detection; identification; Expensive; under development; estimates the relative abundance not quantitative 


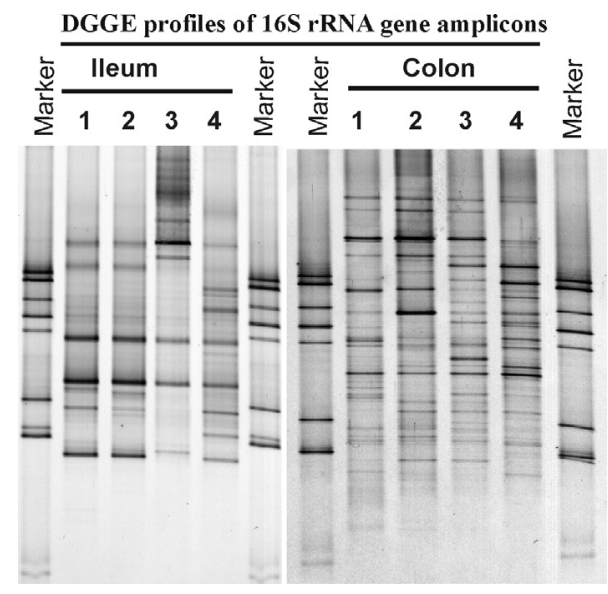

Figure 1. DGGE analysis of 16S rRNA gene PCR products of ileal and colonic samples from four weaning piglets. Ileum, ileal lumen samples of four different piglets indicated as 1,2, 3, 4; Colon, colonic lumen samples of the same piglets $(1,2,3,4)$. M, a marker containing PCR products of known 16S rRNA gene sequences.

and create a healthy GI tract microbiota? Van der Waaij [21] introduced the term "colonisation resistance" to describe the phenomenon that a stable commensal microflora in the intestine prevents invasion by pathogens. In the present paper, we will describe the changes in the GI tract microbiota after weaning, based on general ecological concepts [14]. Special attention is given to the question as to what extent fermentable, non-digestible carbohydrates, as alternatives to antibiotics, can influence the composition of the GI tract microbiota.

\section{RESULTS}

\subsection{Development of the GI tract microbiota in mammalian neonates and adults}

Microbial succession during the first few weeks of life in the alimentary tract of humans, swine, cattle and poultry is remarkably similar. Within a few days of birth, coliforms and streptococci dominate the microbiota in all the above species. Obligate anaerobes appear later. Clostridia and lactobacilli may also be present in most hosts within a short period of time [12]. Earlier studies in pigs using plate counting based techniques have shown that the development of the intestinal microbiota undergoes a rapid ecological succession during the period from birth to weaning [20]. During and after birth, the young animal becomes colonised with a variety of microbes from the birth canal and the immediate environment. The microflora remains fairly stable in terms of species composition after this initial colonisation, and for as long as the piglets receive their sow's milk [13]. However, the introduction of solid feed causes major qualitative and quantitative alterations in the microflora. For example, strict anaerobes such as Bacteroides become established in the large intestine, and this corresponds with a decline in the numbers of facultative anaerobe organisms [17].

A recent application of molecular techniques to study the microbial ecology of human babies has unveiled new trends in bacterial colonisation [3]. Since from a digestive physiological point of view, the pig's intestinal tract is considered to be an appropriate model system for the human intestinal tract, a comparison with the results obtained with humans is valuable [8]. After birth and during the first few days thereafter, often only one phylotype is enriched and dominant in the faeces. This was visualised by DGGE fingerprints of 16S rRNA gene PCR amplicons derived from faecal samples of human babies that were taken at regular intervals after birth. After cloning and sequencing of 16S rRNA, it appeared that the first colonisers often belong to Escherichia coli or Clostridium spp. After a few days, the first signals of Bifidobacterium spp. appeared in the DGGE fingerprint. These remained prominent during the time of breast-feeding. After weaning, the DGGE profiles became more complex and several groups of amplicons 
were replaced by other ribotypes of Clostridium, Ruminococcus, Enterococcus and Enterobacter spp. As the children grew older, the profiles became more complex and more constant in time. The percentage of similarity with known sequences in databases is usually below $97 \%$, indicating that many of those sequences belong to as yet undescribed species. This conclusion is in agreement with studies of adult humans [26]. Earlier studies based on plate counting often reported the occurrence of almost all genera that have been described. The molecular detection of amplicons belonging to Ruminococcus spp. that are not detected by plate counting, demonstrates the advantage of the 16S rRNA gene approach. In contrast, Bacteroides spp. that are often found in faeces by plate counting and in clone libraries, are seldomly found in a DGGE profile [26]. Following molecular analysis of the GI tract microbiota, it is likely that similar results will be found in other mammals including pigs.

\subsection{The influence of fermentable carbohydrates on the GI tract microbiota of weaned piglets}

The effect of fermentable carbohydrates (sugar beet pulp and fructooligo-saccharides) on the faecal bacterial communities of weaning piglets has been reported recently [8]. A combination of $16 \mathrm{~S}$ rRNA-based approaches revealed significant changes in the faecal microbiota immediately after weaning. Piglets fed diets including fermentable carbohydrates showed a higher bacterial diversity and a more rapid stabilisation of the bacterial community compared with those of animals fed with a control diet. Sequence analysis showed that most of the DGGE bands have a low similarity with 16S rRNA gene sequences of known cultured bacteria. Amplicons related to Ruminococcus-like species were found in all DGGE fingerprints derived from pigs on the diet containing sugar beet pulp and fructooligosaccharides, but not in pigs on the control diet. These results indicate that these bacteria may play an important role in the fermentation of dietary fibres in the GI tract of newly weaned piglets.

In a similar manner we analysed the modulation of the bacterial composition in the ileal and colonic lumen of piglets upon the addition of a diet containing four fermentable carbohydrates, namely lactulose, inulin, wheat starch and sugar beet pulp [9]. Comparative molecular microbiological analysis revealed that the principal microbiological difference between the ileal and colonic digesta was the occurrence of a higher number of DGGE bands in the colon compared to the ileum. Moreover, both the number of bacteria and the composition of bacterial communities in the small intestine of weaned piglets were affected by the diet containing fermentable carbohydrates by day 10 of the experiment. The application of quantitative FISH using a newly designed species specific probe revealed that the Lactobacillus amylovorus-like population was the most prevalent in the ileal and colonic lumen samples of the piglets fed for 10 days with fermentable carbohydrates. Animal parameters such as growth and feed intake were not altered by the inclusion of the above mentioned fermentable carbohydrates in the diet. This is contrary to the usual expectation, that such an inclusion will negatively affect the growth of the animal, since it is supposed to reduce the proportion of enzymatically degradable ingredients. Until recently, any part of the diet which was fermented, was considered to have been wasted [24]. The piglets remained in good health throughout the experiment, which is also not surprising, given that this was not a challenge trial. This is a common outcome for animals reared under experimental conditions, due to the comparatively clean environment of the facilities.

These experimental diets used in the above mentioned experiments allowed a comparison to be made between a semipurified diet containing minimal fermentable carbohydrates, and one which had been designed to encourage fermentation along 
the entire tract. Clearly, a semi-purified diet is unlikely to be used by farmers, but it has been shown that ingredients commonly used in pig diets have variable fermentability. It was important to design one that was low in these products. Interestingly though, with the increased interest of EU farmers in diets that will stimulate "colonisation resistance" [21] by intestinal commensal bacteria, fermentable carbohydrates are being increasingly added to such diets, including sugar beet pulp. Improved "colonisation resistance", is unlikely to lead to dramatic changes in the growth of pigs, but it can be expected to provide piglets with improved resistance to pathogenic infection at critical moments such as at weaning [24].

In another feeding trial, the consequences of high amounts of wheat in the diet of weaning piglets were evaluated by conventional microbiological methods [2]. Piglets were weaned at 21 days of age and subsequently stomach tube-fed for 13 days. A simplified diet enriched with wheat and a reference diet were provided. By day 15, the enterobacteria/anaerobes ratio in the jejunum of wheat-fed piglets was significantly higher compared with animals that were fed the reference diet. The high proportion of enterobacteria in the jejunum in the wheat-fed piglets suggests that wheat could indeed favour intestinal disorders.

Further elucidation of the response of small intestinal microbiota of piglets during weaning was assessed using a combination of culture-dependent and molecular techniques in an experiment described recently by Kluess et al. [6]. The influence of different diets (with/without antibiotics, low/high fibre content) upon the bacterial community in the small intestine was analysed. The results showed that under these experimental conditions, the predominant microbial community as well as its metabolites appear to be quite stable during weaning. Dominant bacteria during this time period were lactobacilli, which decreased during the actual weaning process, but re-established to preweaning values soon after, independently of dietary regime. The majority of lactobacilli were related to L. amylovorus or phylotype (OTU) 171 [11], as shown by molecular microbiological techniques based on $16 \mathrm{~S}$ rRNA gene sequence analyses, DGGE and FISH. This phylotype has also recently been found to be the most abundant Lactobacillus phylotype in the GI tract of Danish pigs differing in age and feeding regime [11].

\section{CONCLUDING REMARKS}

Molecular analysis of the composition of the GI tract microbiota has been shown to be a useful tool to monitor the effects of diet and environmental factors on the health of the animal. The addition of fermentable carbohydrates to the diet of weaning piglets leads to an enrichment of lactobacilli in the small intestine and a significantly faster increase in diversity of the microbiota in the colon. It is clear that the analysis of the composition of the microbiota in faeces does not tell us what happens in the small intestine. Moreover, taxonomic diversity of the microbiota only reveals the identity of microorganisms present, but provides only limited information on their potential functional role.

A stable and complex commensal bacterial community, which is lacking a pathogenic invasion, certainly is a prerequisite of a healthy ecosystem! The next logical step would be to focus on the quantification of the activity and functional gene expression of the bacteria in the GI tract using DNA chip technology. Interesting studies by Hooper et al. [5] have demonstrated that GI tract bacteria are involved in the gene expression of the epithelial cells. This cross talk between bacteria and the host may provide answers to major questions, such as "how does the host recognise the GI tract microbiota" and "how does the bacterium know that it is welcome to stay in the GI tract of the host"?

To understand this complex interaction between GI tract microbiota and the host, 
we need interdisciplinary research by immunologists, nutritionists and microbiologists. The further application of the novel DNA chip technology will be of utmost importance to elucidate which prokaryotic and host genes are involved in a healthy GI tract and how the composition and activity of the microbiota can be manipulated in order to control the enrichment of pathogens.

\section{ACKNOWLEDGEMENTS}

This research was financially supported by the European Communities EC project HEALTHYPIGUT (QLK5-LT2000-00522), the National Natural Sciences Foundation in China (grant Nos. 39870588 and 30025034), the Product Board Animal Feed, The Netherlands and the Dutch Academy of Sciences.

\section{REFERENCES}

[1] Cromwell G.L., Why and how antibiotics are used in swine production, Anim. Biotechnol. 13 (2002) 7-27.

[2] Favier C.F., Lallès P.J., Sève B., Intestinal bacteriological changes in piglets after weaning onto a diet based on wheat, Reprod. Nutr. Dev. 42 (2002) 18-19.

[3] Favier C.F., Vaughan E.E., de Vos W.M. Akkermans A.D.L., Molecular monitoring of succession of bacterial communities in human neonates, Appl. Environ. Microbiol. 68 (2002) 219-226.

[4] Heilig H., Zoetendal E.G., Vaughan E.E., Marteau P., Akkermans A.D.L., de Vos W.M., Molecular diversity of Lactobacillus spp. and other lactic acid bacteria in the human intestine as determined by specific amplification of $16 \mathrm{~S}$ ribosomal DNA, Appl. Environ. Microbiol. 68 (2002) 114-123.

[5] Hooper L., Ji G., Commensal host-bacterial relationships in the gut, Science 292 (2001) 1115-1118.

[6] Kluess J., Akkermans A.D.L., Konstantinov S.R., Kuhla S., Kwella M., Souffrant W.B., The microbial community and its metabolic activities in the small intestine of weaning piglets, in: Souffrant W.B., Metges C.C. (Eds.), Progress in research on energy and protein metabolism, Rostock, Germany, 2003, pp. 613618.
[7] Konstantinov S.R., Fitzsimons N., Vaughan E.E., Akkermans A.D.L., From composition to functionality of the intestinal microbial communities, in: Tannock, G.W. (Ed.), Probiotics and Prebiotics: Where are we going? Caister Academic Press, London, 2002, pp. 59-84.

[8] Konstantinov S.R., Zhu W.-Y., Williams B.A., Tamminga S., de Vos W.M., Akkermans A.D.L., Effect of fermentable carbohydrates on faecal bacterial communities as revealed by DGGE analysis of $16 \mathrm{~S}$ rDNA, FEMS Microbiol. Ecol. 43 (2003) 225-235.

[9] Konstantinov S.R., Awati A., Smidt H., Williams A.B., Akkermans A.D.L., de Vos W.M., Specific response of a novel and abundant Lactobacillus amylovorus-like phylotype to dietary prebiotics in the gut of weaning piglets, Appl. Environ. Microbiol. 70 (2004) 3821-3830.

[10] Leser T.D., Vindecrona R.H., Jensen T.K., Jensen B.B., Moller K., Changes in the colon of pigs fed different experimental diet and after infection with Brachyspira hyodysenteriae, Appl. Environ. Microbiol. 66 (2000) 3290-3296.

[11] Leser T.D., Amenuvor J.Z., Jensen T.K., Lindecrona R.H., Boye M., Moller K., Culture-independent analysis of gut bacteria: the pig gastrointestinal tract microbiota revisited, Appl. Environ. Microbiol. 68 (2002) 673-690.

[12] Mackie R.I., Sghir A., Gaskins H.R., Developmental microbial ecology of the neonatal gastrointestinal tract, Am. J. Clin. Nutr. 69 (Suppl.) (1999) 1035S-1045S.

[13] Mathew A.G., Upchurch W.G., Chattin S.E., Incidence of antibiotic resistance in fecal Escherichia coli isolated from commercial swine farms, J. Anim. Sci. 76 (1998) 429-434.

[14] Molles M.C., Ecology: concepts and applications, WCB McGraw-Hill, Boston, 1999, Context.

[15] Olsen G., Lane D., Giovannoni S., Pace N., Stahl D., Microbial ecology and evolution: a ribosomal RNA approach, Annu. Rev. Microbiol. 40 (1986) 337-365.

[16] Pryde S.E., Richardson A.J., Stewart C.S., Flint H.J., Molecular analysis of the microbial diversity present in the colonic wall, colonic lumen, and cecal lumen of a pig, Appl. Environ. Microbiol. 65 (1999) 5372-5377.

[17] Savage D.C., Microbial ecology of the gastrointestinal tract, Annu. Rev. Microbiol. 31 (1977) 107-133.

[18] Simpson J.M., McCracken V.J., Gaskins H.R., Mackie R.I., Denaturing gradient gel electrophoresis analysis of $16 \mathrm{~S}$ ribosomal DNA amplicons to monitor changes in fecal bacterial populations of weaning pigs after 
introduction of Lactobacillus reuteri strain MM53, Appl. Environ. Microbiol. 66 (2000) 4705-4714.

[19] Spreeuwenberg M.A.M., Verdonk J.M.A.J., Gaskins H.R., Verstegen M.W.A., Small intestine epithelial barrier function is compromised in pigs with low feed intake at weaning, J. Nutr. 131 (2001) 1520-1527.

[20] Stewart C.S., Microorganisms in hindgut fermentors, in: Mackie R.I., White B.A., Isaacson R.E. (Eds.), Gastrointestinal Microbiology, Chapman and Hall, New York, 1997, pp. 142186.

[21] Van der Waaij D., The ecology of the human intestine and its consequences for the overgrowth of pathogens such as Clostridium difficile, Ann. Rev. Microbiol. 43 (1989) 69-87.

[22] Vaughan E.E., Schut F., Heilig H.G.H.J., Zoetendal E.G., de Vos W.M., Akkermans A.D.L., A molecular view of the intestinal ecosystem, Curr. Issues Intest. Microbiol. 1 (2000) 1-12.

[23] Verstegen M.W., Williams B.A., Alternatives to the use of antibiotics as growth promotors for monogastric animals, Anim. Biotechnol. 13 (2002) 113-127.

[24] Williams B.A., Verstegen M.W.A., Tamminga S., Fermentation in the large intestine of single-stomached animals and its relationship to animal health, Nutr. Res. Rev. 14 (2001) 207227.

[25] Woese C.R., Bacterial evolution, Microbiol. Rev. 51 (1987) 221-271.

[26] Zoetendal E.G., Akkermans A.D., de Vos W.M., Temperature gradient gel electrophoresis analysis of $16 \mathrm{~S}$ rRNA from human fecal samples reveals stable and host-specific communities of active bacteria, Appl. Environ. Microbiol. 64 (1998) 3854-3859. 